\title{
Seasonal variation and natural infection of Lutzomyia antunesi (Diptera: Psychodidae: Phlebotominae), an endemic species in the Orinoquia region of Colombia
}

\author{
Adolfo Vásquez Trujillo ${ }^{1 /+}$, Angélica E González Reina ${ }^{1}$, Agustín Góngora Orjuela ${ }^{2}$, \\ Edgar Prieto Suárez ${ }^{3}$, Jairo Enrique Palomares ${ }^{4}$, Luz Stella Buitrago Alvarez ${ }^{5}$ \\ ${ }^{1}$ Corporación para la Investigación en Salud Tropical, Villavicencio, Meta, Colombia ${ }^{2}$ Escuela de Ciencias Animales, Universidad de los Llanos, \\ Villavicencio, Meta, Colombia ${ }^{3}$ Departamento de Salud Pública, Facultad de Medicina, Universidad Nacional de Colombia, \\ Bogotá DC, Colombia ${ }^{4}$ Clinical Sciences Department, Colorado State University, Fort Collins, CO, USA \\ ${ }^{5}$ Laboratorio de Entomología, Secretaria de Salud del Meta, Villavicencio, Meta, Colombia
}

Lutzomyia antunesi has been commonly reported in outbreaks of cutaneous leishmaniasis (CL) in the Orinoquia region of Colombia. The bionomics of this species were studied in the municipality of Villavicencio (Meta, Colombia). Sandflies were captured over the course of one week per month for one year in intradomiciliary, peridomiciliary and extradomiciliary housing areas. The captures were performed from 06:00 pm-06:00 am using CDC light traps and the females were processed for polymerase chain reaction (PCR) to detect Leishmania spp. A total of 22,097 specimens and 19 species were captured of which Lu. antunesi (89\%) and Lutzomyia walkeri (5\%) were the most abundant. Other species recognised as anthropophilic (Lutzomyia panamensis, Lutzomyia gomezi, Lutzomyia flaviscutellata and Lutzomyia fairtigi) were present in very low abundance $(<2 \%)$. Natural infection with Leishmania spp was detected using PCR in Lu. antunesi, Lu. panamensis and Lu. flavicutellata, showing infection rates of $1 \%$, $4.8 \%$ and $7.5 \%$, respectively. The present paper provides information on various ecological aspects of $\mathrm{Lu}$. antunesi. An analysis of seasonality shows that this species increases in abundance in the hottest months (December, January and February), directly correlating with the maximum temperature and inversely correlating with precipitation. The natural infection rate is associated with the peaks of highest abundance.

Key words: sandflies - seasonal variation - natural infection - Lutzomyia antunesi - leishmaniasis - Colombia

The number of cases of American cutaneous leishmaniasis (ACL) per year in the department of Meta (ME) of Colombia has increased during the last decade (139 in 2005 to 1,062 in 2012) (SIVIGILA 2012). Since 2005, several outbreaks have been recorded in different municipalities and are mainly related to new human settlements in rural areas that have been affected by different social factors (Velez et al. 2001); peridomiciliary transmission has been reported (INS 2012). This epidemiological profile has been associated with legal or illegal urbanisations in deforested areas of Villavicencio.

Lutzomyia antunesi (Coutinho, 1939) is likely the primary ACL vector in ME. This fly is naturally infected with Leishmania (Leishmania) chagasi in Brazil (Ryan et al. 1984) and it has been determined that this species plays an important role in the transmission of Leishmania (Viannia) lindenbergi (Silveira et al. 2002). The first report of leishmaniasis infection in Colombia involved the observation of undetermined flagellates in an ACL focus in a case of intradomiciliary and peridomiciliary

doi: 10.1590/0074-0276108042013011

+Corresponding author: adolfovasquezmvz@gmail.com

Received 15 August 2012

Accepted 10 April 2013 transmission (Ferro et al. 1997). Natural infection with Leishmania spp was recently confirmed (Vásquez-Trujillo et al. 2008).

Preliminary studies have been conducted in Colombia to assess the existing sandfly fauna associated with ACL transmission areas (Montoya-Lerma \& Ferro 1999, Barreto et al. 2000, Bejarano 2006). Recent studies investigating $\mathrm{Lu}$. antunesi have determined its relative abundance, vector-human contact, the presence of Leishmania parasites and sandflies in the same geographical area and the detection of these parasites in insects and domestic animals (Vásquez-Trujillo 2006, Vásquez-Trujillo et al. 2008), thereby fulfilling some criteria for vector incrimination (Young \& Lawyer 1987, Killick-Kendrick 1990). However, environmental determinants and their relationship with seasonal abundance and infection have not yet been studied. This study aimed to increase the knowledge of Lutzomyia species and to determine the effects of seasonal variations in $L u$. antunesi abundance and infection with Leishmania spp in an ACL-endemic area of Villavicencio.

\section{MATERIALS AND METHODS}

Study area - The study was conducted in a rural area near Villavicencio, northern ME, a subregion of the Eastern Plains (Llanos Orientales) region on the border of the western Andean foothills of Colombia, which together form part of the Colombian Orinoquia ecoregion. Samples were collected in three rural areas: La Re- 
forma (44ㅇ' $\left.81^{\prime \prime} \mathrm{N} 73^{\circ} 28^{\prime} 34^{\prime \prime} \mathrm{W}\right)$, Barcelona $\left(4^{\circ} 39^{\prime} 05^{\prime \prime} \mathrm{N}\right.$ $\left.73^{\circ} 35^{\prime} 68^{\prime \prime} \mathrm{W}\right)$ and Cocuy $\left(4^{\circ} 24^{\prime} 94^{\prime \prime} \mathrm{N} 73^{\circ} 36^{\prime} 36^{\prime \prime} \mathrm{W}\right)$, located $12 \mathrm{~km}, 4 \mathrm{~km}$ and $7 \mathrm{~km}$ away from Villavicencio, respectively (Fig. 1). These sites have similar environmental conditions, including an elevation $380 \mathrm{~m}$ above sea-level, an average temperature of $25^{\circ} \mathrm{C}, 85 \%$ relative humidity $(\mathrm{RH})$ and 3,600 $\mathrm{mm}$ annual rainfall according to the Colombian Institute of Hydrology, Meteorology and Environmental Studies (IDEAM). Sampling was conducted from June 2008-May 2009, encompassing both the wet and dry periods. The area is characterised as premontane humid tropical forest and has some elements of humid tropical forest (Holdrige 1967).

Lutzomyia capture sites, collection and identification - A preliminary study was conducted on all properties in La Reforma (21), Barcelona (82) and Cocuy (44) to establish a rough composition of the populations of Lutzomyia species present in these areas and to determine which properties had the highest abundance of sandflies. Those properties with the highest abundance were then selected as monthly follow-up units (MFUs) for further longitudinal sampling. The preliminary study used CDC-type light traps placed $1.5 \mathrm{~m}$ above the ground in peridomiciliary areas, $15 \mathrm{~m}$ away from the houses; collections were performed between 06:00 pm-06:00 am.

Seasonal sampling was then conducted at three dwellings selected as MFUs according to the following selection criteria: (i) the houses were a minimum distance of $200 \mathrm{~m}$ away from the forest, (ii) there was a recent registry of confirmed cases of ACL in humans or canines and (iii) the inhabitants provided informed consent. Intradomiciliary, peridomiciliary and extradomiciliary sites (forests adjacent to the dwellings located a minimum of $200 \mathrm{~m}$ away) were sampled as capture habitats. The sampling lasted for one week per month over a 12-month period, simultaneously in the three rural areas, from June 2008-May 2009.

The sandflies collected were transferred to the Laboratory of Entomology of Department of Health of Meta, sacrificed at $0^{\circ} \mathrm{C}$ and stored in Eppendorf tubes with $70 \%$ ethanol at $4^{\circ} \mathrm{C}$ until taxonomic identification was conducted. A clarifying process was performed to identify male sandflies according to the methodology reported by Maroli et al. (1997). Female taxonomic classification was based on the following characteristics: fifth

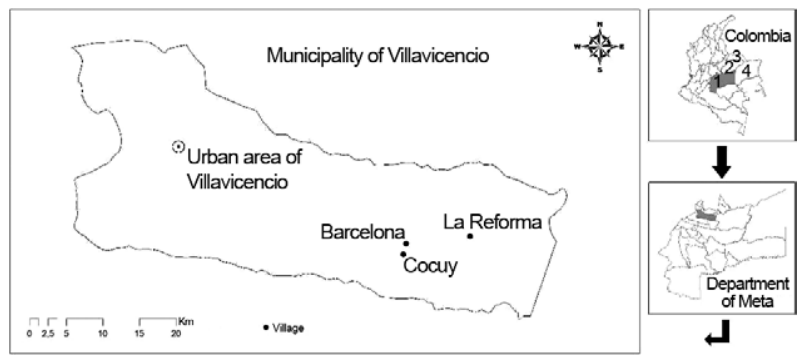

Fig. 1: geographic location of the study area in Colombia and in department of Meta compound of the villages Barcelona, Cocuy and La Reforma. 1: Meta; 2: Casanare; 3: Arauca; 4: Vichada. palp length, scutum pigmentation, flagellomere length and alpha and beta veins in the wings and spermathecae. For males, all taxonomic characteristics were evaluated after the clarifying process. The classification used was based on Young and Duncan (1994).

Determination of natural infection - Natural infection was determined by polymerase chain reaction (PCR). DNA was extracted using the phenol-chloroform protocol described by Golczer and Arrivillaga (2008) and amplified by the protocol standardised by Cabrera et al. (2002) using the Leishmania genus-specific OL1 and OL2 universal primers, which target kinetoplast minicircle DNA (Romero et al. 2001). This test was only performed for Lutzomyia species that had a vector-related background. The Lutzomyia species were tested in pools with a maximum of 30 insects classified by capture habitat (intradomiciliary, peridomiciliary and extradomiciliary) and by capture month. The head and thorax of the insects were used in an attempt to obtain infective forms only from the upper digestive tract.

Statistical analysis - Seasonal variation was evaluated first by transforming the variable "abundance" into its natural logarithm plus one $[\operatorname{logn}(y+1)]$ and a one-way ANOVA was performed, followed by Tukey's multiple comparison test $(95 \%$ confidence level). Spearman's rank correlation non-parametric test $(\rho)$ was used to evaluate the correlations between the abundance and environmental determinants. Data regarding the daily maximum, minimum and average temperatures, maximum, minimum and average daily rainfall and daily RH were obtained from the weather station closest to the sampling sites in the IDEAM weather station network (Unillanos station: 3503507, main climate type). Data were also obtained for one, two and 15 days prior to sampling to determine the relationship between the abundance and preceding daily climatic variables.

\section{RESULTS}

A total of 14,553 Lutzomyia specimens were collected during the preliminary sampling. The most abundant species was $L u$. antunesi $(63 \%, 86 \%$ and $93.3 \%$ of the total specimens captured in Barcelona, Cocuy and La Reforma, respectively), followed by Lutzomyia walkeri $(35 \%, 17 \%$ and $6 \%)$, Lutzomyia gomezi $(0.4 \%, 0 \%$ and $2.5 \%)$ and Lutzomyia panamensis (1\%, $0.4 \%$ and $1 \%)$. For the selected MFUs, 4,356 Lutzomyia per trap/night were obtained from a dwelling in the Barcelona rural area, 3,413 Lutzomyia per trap/night from the Cocuy rural area and 1,034 Lutzomyia per trap/night in the La Reforma rural area.

A total of 22,094 Lutzomyia specimens were captured during the seasonal sampling. The evaluation of the richness observed at each habitat revealed seven species captured in the intradomiciliary areas, 18 in the peridomiciliary areas and 19 in the extradomiciliary areas. The most abundant species was Lu. antunesi (89\%), followed by various species with vector backgrounds: $L u$. panamensis (2.3\%), Lutzomyia flaviscutellata $(1.05 \%)$, Lu. gomezi (0.8\%) and Lutzomyia fairtigi $(0.6 \%)$ (Table I). The seasonal variation analysis obtained by ANOVA 


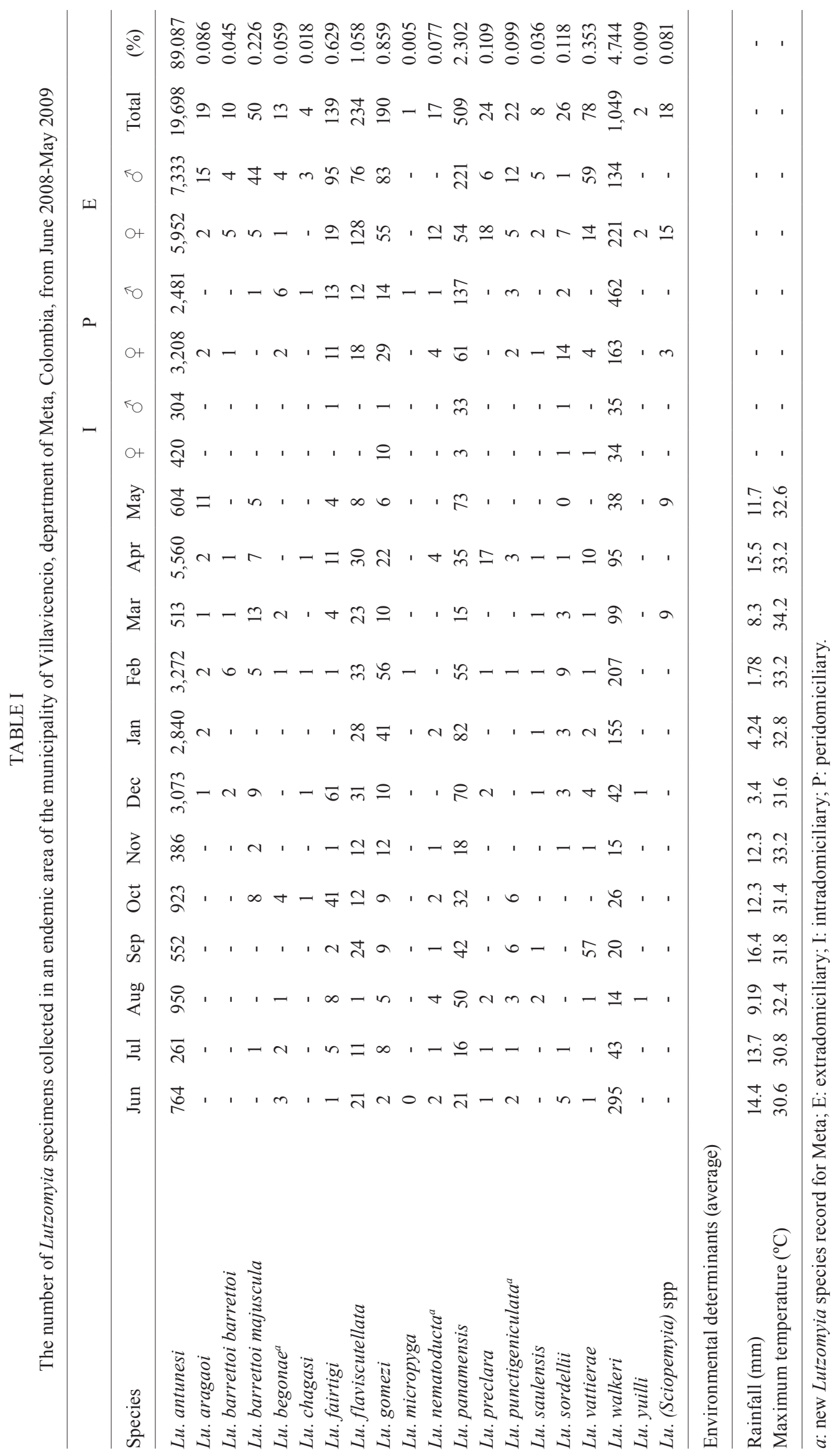


showed that only total $L u$. antunesi $(\mathrm{F}=4.99 ; \mathrm{p}<0.001)$ and $L u$. antunesi at extradomiciliary sites $(\mathrm{F}=5.99 ; \mathrm{p}$ $<0.001)$ exhibited significant seasonal variation. These groups had different rates of abundance during the sampling months of December $(\mathrm{t}=2.212 ; \mathrm{p}=0.0367)$, January $(\mathrm{t}=2.237 ; \mathrm{p}=0.0257)$, February $(\mathrm{t}=2.343 ; \mathrm{p}=$ $0.0277)$ and April $(\mathrm{t}=3.162 ; \mathrm{p}=0.004)$ and these months exhibited the highest abundance according to Tukey's multiple comparison test.

An analysis of Spearman's correlation revealed that rainfall was the variable that best explained the total abundance of Lutzomyia species $(\rho=-0.704 ; \mathrm{p}<0.0001)$. $\mathrm{Lu}$. antunesi (the most abundant species) had a similar pattern and was similarly affected by rainfall $(\rho=-0.688$; $\mathrm{p}<0.0001$ ) (Fig. 2). Other environmental determinants, such as the maximum temperature one day before sampling and the minimum temperature two days before sampling, positively correlated with the $L u$. antunesi abundance in all capture habitats. The maximum temperature $\left(29-31^{\circ} \mathrm{C} ; \rho=0.627 ; \mathrm{p}<0.0001\right)$ was the variable that most significantly correlated with $L u$. gomezi, whereas the maximum temperature one day before sampling $(\rho=0.419 ; p=0.0110)$ and rainfall were the main environmental variables $(\rho=-0.408 ; p=0.0136)$ that correlated with Lu. flaviscutellata and Lu. panamensis, respectively (Table II).

A total of 10,760 female Lutzomyia were assessed by PCR to investigate the rate of natural infection. The evaluated species were $L u$. antunesi, Lu. panamensis, Lu. gomezi and Lu. flaviscutellata. The monthly infection rates obtained primarily correlated with the months that had the least rainfall (November-February) and those months for which the high abundance was recorded (December, January and April). Lu. antunesi was found to be an important species, as it was the most abundant, and also had the most consistent monthly infection rates. The importance of $\mathrm{Lu}$. flaviscutellata, Lu. panamensis and $L u$. gomezi as vectors was also confirmed, as they were found to be naturally infected despite very low abundance rates compared to $\mathrm{Lu}$. antunesi (Table III).

\section{DISCUSSION}

Of the total species identified in this study, Lutzomyia begonae, Lutzomyia nematoducta and Lutzomyia punctigeniculata were identified for the first time in ME. $L u$. begonae has been identified in other departments that have different ecological characteristics, such as Guaviare (Cabrera et al. 2009), and the species is always associated with wooded areas. Lu. nematoducta and $L u$.

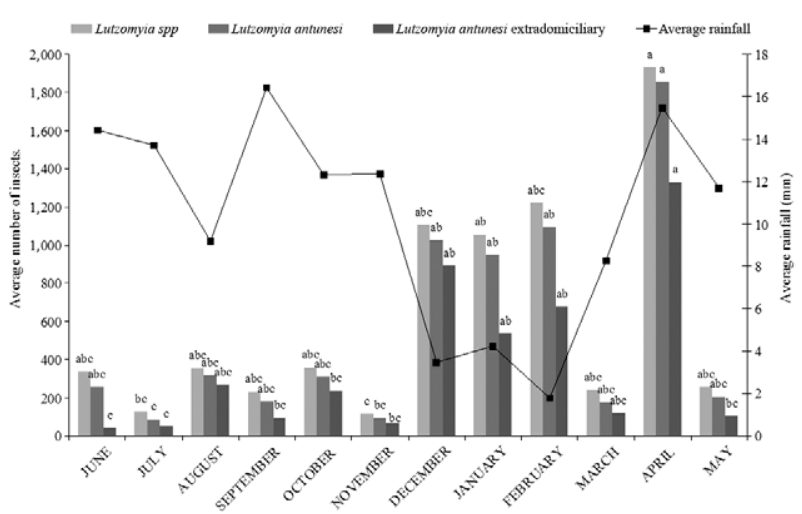

Fig. 2: average monthly total of Lutzomyia, Lutzomyia antunesi and Lutzomyia antunesi extradomiciliary population and monthly rainfall reported for the endemic area of the municipality of Villavicencio, department of Meta, Colombia, from June 2008-May 2009. There were no significant differences for groups having the same letter.

TABLE II

Environmental determinants correlated with the most abundant Lutzomyia species in the municipality of Villavicencio, department of Meta, Colombia

\begin{tabular}{|c|c|c|c|c|c|c|c|c|}
\hline & \multicolumn{2}{|c|}{$\begin{array}{l}\text { Rainfall } \\
\text { (mm) }\end{array}$} & \multicolumn{2}{|c|}{$\begin{array}{l}\text { Maximum temperature } \\
\qquad\left({ }^{\circ} \mathrm{C}\right)\end{array}$} & \multicolumn{2}{|c|}{$\begin{array}{c}\text { Maximum temperature } \\
<1 \text { day } \\
\left({ }^{\circ} \mathrm{C}\right)\end{array}$} & \multicolumn{2}{|c|}{$\begin{array}{c}\text { Minimum temperature } \\
<2 \text { days } \\
\left({ }^{\circ} \mathrm{C}\right)\end{array}$} \\
\hline & $\rho$ & $\mathrm{p}$ & $\rho$ & $\mathrm{p}$ & $\rho$ & $\mathrm{p}$ & $\rho$ & $\mathrm{p}$ \\
\hline Total & -0.704 & $<0.0001$ & 0.26 & 0.1256 & 0.378 & 0.0232 & 0.431 & 0.0086 \\
\hline Lu. antunesi & -0.688 & $<0.0001$ & 0.257 & 0.1296 & 0.382 & 0.0216 & 0.441 & 0.0071 \\
\hline Lu. antunesi (I) & -0.507 & 0.0016 & 0.21 & 0.2201 & 0.346 & 0.0385 & 0.337 & 0.0446 \\
\hline Lu. antunesi $(\mathrm{P})$ & -0.509 & 0.0015 & 0.227 & 0.1829 & 0.55 & 0.0005 & 0.18 & 0.2939 \\
\hline Lu. antunesi $(\mathrm{E})$ & -0.579 & 0.0002 & 0.364 & 0.0291 & 0.266 & 0.1171 & 0.527 & 0.0010 \\
\hline Lu. flaviscutellata & -0.384 & 0.0209 & 0.307 & 0.0688 & 0.419 & 0.0110 & 0.356 & 0.0333 \\
\hline Lu. panamensis & -0.408 & 0.0136 & 0.378 & 0.0230 & 0.342 & 0.0410 & 0.326 & 0.0525 \\
\hline Lu. gomezi & -0.122 & 0.4779 & 0.627 & $<0.0001$ & 0.383 & 0.0211 & 0.335 & 0.0457 \\
\hline Lu. gomezi $(\mathrm{E})$ & -0.143 & 0.4059 & 0.566 & 0.0003 & 0.307 & 0.0683 & 0.334 & 0.0462 \\
\hline
\end{tabular}

significant Spearman's coefficient of correlation $(\rho)$ values regarding an alpha threshold $=0.05$ are shown in bold. E: extradomiciliary; I: intradomiciliary; P: peridomiciliary. 
punctigeniculata were found in both peridomiciliary and extradomiciliary areas, though they exhibited higher abundance in extradomiciliary habitats. Lu. antunesi, Lu. panamensis and Lu. gomezi were the most abundant species in all the capture habitats, demonstrating their adaptation to anthropophilic settings where blood meal sources and possible breeding sites can be found. Therefore, dwellings and their surrounding areas are high-risk areas for acquiring ACL (Pardo et al. 2006, Santamaría et al. 2006), which is evident from previous studies conducted in the area (Vásquez-Trujillo et al. 2008).

The ecological behaviour of an ACL focus encompasses different characteristics: its niche, its reservoirs, the vector and its seasonal abundance pattern, which is influenced by environmental determinants. Molina et al. (2008) showed that Lutzomyia fairtigi underwent a seasonal variation in the department of Casanare that was mainly determined by increased rainfall $(\rho=0.675 ; p<$ 0.001 ), whereas no changes in abundance or any association with environmental determinants were recorded for Lu. antunesi throughout the year. In contrast, the present study showed that $L u$. antunesi exhibited a seasonal variation in abundance $(\mathrm{F}=4.990 ; \mathrm{p}<0.001)$ that was determined by rainfall $(\rho=-0.688 ; p<0.001)$, with abundance increasing during the hottest months and in the absence of rain (maximum temperature 1 day before sampling) $(\rho=0.55 ; p<0.001)$. These differing results demonstrate that a particular species can behave differently depending on the local environmental conditions, its niche adaptation, food sources, soil and other factors that dominate and thereby affect Leishmania transmission in the area.

The increased Lutzomyia abundance determined by temperature (maximum temperature 1 and 2 days before sampling) could be explained by increased physiological lifecycle activity (Killick-Kendrick 1978, Ready \& Croset 1980), primarily consisting of nocturnal activity patterns and biting behaviour (Morrison et al. 1995, González et al. 1999, Souza et al. 2002). Conversely, reduced rainfall abundance could be related to the reduced physiological activity of fourth-instar larvae (Killick-Kendrick 1978) or mechanical effects on breeding sites (wash out).

Importantly, the opposite effect was observed during the months with the highest precipitation, specifically September and April. This result is expected for September based on the correlation model obtained, which demonstrates an inverse effect between rain and abundance (Table II). However, in April, the abundance of Lutzomyia species increased despite the high rainfall (Fig. 2), which can be explained by the transition from summer to winter and its effect on the soil conditions, low water table, low saturation and high temperatures. These factors benefit the development of the larval stage, as opposed to September when rains were continuous and the temperature was two degrees lower (Table I).

With regard to $L u$. gomezi, the increased abundance observed during the dry months (December, January and February) agreed with previous studies conducted in Venezuela (Feliciangeli 1987). In contrast, the behaviour of Lu. panamensis was different from a previous study by González et al. (1999), reporting that Lu. panamensis abundance increased dramatically with rainfall.

In terms of natural infection, $L u$. flaviscutellata, $L u$. panamensis and Lu. gomezi were confirmed as potential cutaneous leishmaniasis vectors in the rural areas of Villavicencio due to their constant infection rates, mainly during dry months (November-February), despite their very low abundance, particularly in wooded (extradomiciliary) areas (Table I). Studies conducted in the wild ar-

\section{TABLE III}

Monthly natural infection rate (\%) regarding the most abundant Lutzomyia species in the municipality of Villavicencio, department of Meta, Colombia, Colombia

\begin{tabular}{|c|c|c|c|c|c|c|c|c|}
\hline & Lutzomyia & I & $\mathrm{P}$ & $\mathrm{E}$ & Lu. antunesi & Lu. flaviscutellata & Lu. panamensis & Lu. gomezi \\
\hline June & 0 & 0 & 0 & 0 & 0 & 0 & 0 & 0 \\
\hline July & 0 & 0 & 0 & 0 & 0 & 0 & 0 & 0 \\
\hline August & 1.92 & 4.8 & 9.3 & 0.92 & 0.44 & 16 & 19 & 0 \\
\hline September & 0 & 0 & 0 & 0 & 0 & 0 & 4 & 66 \\
\hline October & 0 & 0 & 0 & 0 & 0 & 0 & 0 & 0 \\
\hline November & 8.2 & 42 & 10.1 & 3.7 & 4.7 & 57 & 25 & 40 \\
\hline December & 1.06 & 0 & 2.2 & 0.85 & 0.42 & 5.8 & 10.5 & 33 \\
\hline January & 4.9 & 64 & 0.51 & 3.7 & 4.7 & 5.5 & 7.6 & 15 \\
\hline February & 0.27 & 0 & 0.35 & 0.26 & 0.12 & 12.5 & 0 & 0 \\
\hline March & 0 & 0 & 0 & 0 & 0 & 0 & 0 & 0 \\
\hline April & 0.12 & 0 & 0.4 & 0 & 0.13 & 0 & 0 & 0 \\
\hline May & 0 & 0 & 0 & 0 & 0 & 0 & 0 & 0 \\
\hline \multirow[t]{2}{*}{ Total } & 1.25 & 11.6 & 0.6 & 0.8 & 1.02 & 7.53 & 3.32 & 10.3 \\
\hline & $135 / 10,760$ & $56 / 479$ & $24 / 3,606$ & $54 / 6,675$ & $99 / 9,707$ & $11 / 146$ & $15 / 452$ & $9 / 87$ \\
\hline
\end{tabular}

E: extradomiciliary; I: intradomiciliary; P: peridomiciliary. 
eas of the department of Guaviare have shown that $L u$. flaviscutellata can act as a vector due to its anthropophilic behaviour (Cabrera et al. 2009). This fly predominates in the woods and savannahs of Brazil, has been implicated in the transmission of Leishmania (Leishmania) amazonensis and identified as a possible vector of ACL in the state of Bolívar, in Venezuela (González \& Devera 1999, Ribeiro et al. 2007, da Silva et al. 2010).

$L u$. gomezi and Lu. panamensis have been proposed as vectors for Leishmania (Viannia) braziliensis and Leishmania (Viannia) panamensis in Venezuela and Panamá (Christensen et al. 1983, Rodríguez et al. 1999). These species are widely distributed throughout Colombia and are present in 18 of 32 departments (Bejarano 2006). Furthermore, it has been demonstrated that these species have a great ability to adapt to environmental changes in their habitat (Travi et al. 2002). Lu. gomezi and $L u$. panamensis were incriminated as vectors in a suburban focus of visceral leishmaniasis in Chicamocha Canyon (Sandoval et al. 2006) and natural infection with $L$. $(V$.) panamensis has been recently found in areas of human activity in the department of Boyacá (0.5-0.6\% natural infection rates) (Santamaría et al. 2006).

Conversely, $\mathrm{Lu}$. antunesi exhibited infection rates of $0.1-4.7 \%$, which agree with the rates described in the literature (Travi et al. 1988). Lu. antunesi stands out as the dominant species in the study area, as it is present in both anthropophilic (intradomiciliary and peridomiciliary) and extradomiciliary areas in great abundance (85\%, $85 \%$ and $91 \%$ for each habitat). Even though this species has not been considered to be medically important in Colombia, it has been identified in regions with high ACL incidence and comprises equal or higher population percentages compared to species that have already been incriminated, indicating that it could be present for disease transmission (Sandoval et al. 2006). Ryan et al. (1984) first identified the natural infection of $\mathrm{Lu}$. antunesi in Brazil with the presence of flagellate forms in a focus of visceral leishmaniasis. The first epidemiological nexus in Colombia was registered in the department of Amazonas where Lu. antunesi is considered an important species because it was present in high abundance in rural and periurban intradomiciliary and peridomiciliary areas of the municipality of Leticia during an active focus (Ferro et al. 1997). Natural infection with Leishmania spp was recently identified in an ACL focus in the rural area of Villavicencio (1.6\% infection rate) (Vásquez-Trujillo et al. 2008).

Increased $L u$. antunesi abundance in anthropophilic areas and gallery forest, mainly during dry months, coupled with evidence of natural infection with Leishmania spp highlights the epidemiological importance of this endemic species in Colombia's Orinoquia region and the possible role it plays in parasite transmission in ME.

\section{ACKNOWLEDGEMENTS}

To Dr Martha Ayala and Parasitology Group (RNL), for the donation of reference strains of Leishmania, and Entomology Group from the National Institutes of Health, for their constant support.

\section{REFERENCES}

Barreto M, Burbano ME, Barreto P 2000. Lutzomyia sand flies (Diptera: Psychodidae) from middle and lower Putumayo department, Colombia, with new records to the country. Mem Inst Oswaldo Cruz 95: 633-639.

Bejarano EE 2006. Lista actualizada de psicódidos (Diptera: Psychodidae) de Colombia. Folia Entomol Mexic 45: 47-56.

Cabrera OL, Mosquera L, Santamaría E, Ferro C 2009. Flebótomos (Diptera: Psychodidae) del departamento de Guaviare, Colombia, con nuevos registros para el país. Biomedica 29: 73-86.

Cabrera OL, Munstermann LE, Cárdenas R, Gutiérrez R, Ferro C 2002. Definición de las condiciones de temperatura y almacenamiento adecuadas en la detección de ADN de Leishmania por PCR en flebotominos. Biomedica 22: 296-302.

Christensen HA, Fairchild GB, Herrer A, Johnson CM, Young DG, de Vásquez AM 1983. The ecology of cutaneous leishmaniasis in the Republic of Panama. J Med Entomol 20: 463-484.

da Silva PES, Alves de Freitas R, Ferreira da Silva D, Alencar RB 2010. Fauna de flebotomíneos (Diptera: Psychodidae) de uma reserva de campina no estado do Amazonas e sua importância epidemiológica. Rev Soc Bras Med Trop 43: 78-81.

Feliciangeli MD 1987. Ecology of sandflies (Diptera: Psychodidae) in a restricted focus of cutaneous leishmaniasis in northern Venezuela. IV. Sandfly monthly fluctuation and leishmaniasis incidence relationship. Mem Inst Oswaldo Cruz 82: 177-179.

Ferro C, Pardo R, Díaz A, Pérez L, Munstermann L 1997. Composición de la fauna de flebotomíneos, género Lutzomyia, de la periferia de la ciudad de Leticia, Amazonas, Colombia. Congreso Internacional Investigación y Salud, INS 80 años 1917-1997. Biomédica 17 (Suppl. 1): 84-85.

Golczer G, Arrivillaga J 2008. Modificación de un protocolo estándar de extracción de ADN para flebotominos pequeños (Phlebotominae: Lutzomyia). Rev Colomb Entomol 34: 199-202.

González R, de Sousa L, Devera R, Jorquera A, Ledezma E 1999. Seasonal and nocturnal domiciliary human landing/biting behaviour of Lutzomyia (Lutzomyia) evansi and Lutzomyia (Psychodopygus) panamensis (Diptera: Psychodidae) in a periurban area of a city on the Caribbean coast of eastern Venezuela (Barcelona, Anzoátegui state). Trans R Soc Trop Med Hyg 93: 361-364.

González R, Devera R 1999. Fauna flebotomínica (Diptera, Psychodidae, Phlebotominae) do estado Bolívar, Venezuela. Rev Soc Bras Med Trop 32: 721-723.

Holdrige LR 1967. Life zone ecology, Tropical Science Center, San José, 206 pp.

INS - Instituto Nacional de Salud 2012. Informe del evento leishmaniasis hasta decimo periodo epidemiológico del año 2012. Available from: ins.gov.co/lineas-de-accion/Subdireccion-Vigilancia/ Informe $\% 20 \mathrm{de} \% 20$ Evento $\% 20$ Epidemiolgico/LEISHMANIASIS\%20Periodo\%20X\%202012.pdf.

Killick-Kendrick R 1978. Recent advances and outstanding problems in the biology of phlebotomine sandflies. Acta Trop 35: 297-313.

Killick-Kendrick R 1990. Phlebotomus vector of the leishmaniasis: a review. Med Vet Entomol 4: 1-24.

Maroli M, Feliciangeli MD, Arias J 1997. Métodos de captura, conservación y montaje de los flebotomos (Diptera: Psychodidae), OPS/OMS/HCP/HCT/95/97, Washington, p. 1-67.

Molina JA, Ortiz MI, Guhl F 2008. Seasonality of Lutzomyia fairtigi (Diptera: Psychodidae: Phlebotominae), a species endemic to eastern Colombia. Mem Inst Oswaldo Cruz 103: 477-482. 
Montoya-Lerma J, Ferro C 1999. Flebótomos (Diptera: Psychodidae) de Colombia. In G Amat, MG Andrade, F Fernández (eds.), Insectos de Colombia, Vol. II, Colección Jorge Álvarez Lleras, 13, Academia Colombiana de Ciencias Exactas, Físicas and Naturales, Bogotá, 211-245.

Morrison AC, Ferro C, Pardo R, Torres M, Wilson ML, Tesh RB 1995. Nocturnal activity patterns of Lutzomyia longipalpis (Diptera: Psychodidae) at an endemic focus of visceral leishmaniasis in Colombia. J Med Entomol 32: 605-617.

Pardo RH, Cabrera OL, Becerra J, Fuya P, Ferro C 2006. Lutzomyia longiflocosa as suspected vector of cutaneous leishmaniasis in a focus of cutaneous leishmaniasis in the sub-Andean region of the Tolima department, Colombia, and knowledge on sandflies by the inhabitants. Biomedica 26 (Suppl. 1): 95-108.

Ready PD, Croset H 1980. Diapause and laboratory breeding of Phlebotomus perniciosus newstead and Phlebotomus ariasi Tonnoir (Diptera: Psychodidae) from southern France. Bull Entomol Res 70: $511-523$

Ribeiro AL, Missawa NA, Zeilhofer P 2007. Distribution of phlebotomine sandflies (Diptera: Psychodidae) of medical importance in Mato Grosso state, Brazil. Rev Inst Med Trop S Paulo 49: 317-321.

Rodríguez N, Aguilar CM, Barrios A, Barrer DC 1999. Detection of Leishmania braziliensis in naturally infected individual sand flies by the polymerase chain reaction. Trans $R$ Soc Trop Med Hyg 93: 47-49.

Romero GA, Guerra MV, Paes MG, Cupolillo E, Bentin Toaldo C, Macêdo VO, Fernandes O 2001. Sensitivity of the polymerase chain reaction for the diagnosis of cutaneous leishmaniasis due to Leishmania (Viannia) guyanensis. Acta Trop 79: 225-229.

Ryan L, Silveira FT, Lainson R, Shaw JJ 1984. Leishmanial infections in Lutzomyia longipalpis and L. antunesi (Diptera: Psychodidae) on the island of Marajó, Pará state, Brazil. Trans R Soc Trop Med Hyg 78: 547-548.

Sandoval CM, Gutiérrez R, Cárdenas R, Ferro C 2006. Species of Lutzomyia (Psychodidae, Phlebotominae) in endemic cutaneous and visceral leishmaniasis foci of the department of Santander, in the eastern range of the Colombian Andes. Biomedica 26 (Suppl. 1): $218-227$.

Santamaría E, Ponce N, Zipa Y, Ferro C 2006. Presencia en el peridomicilio de vectores infectados con Leishmania (Viannia) panamensis en dos focos endémicos en el occidente de Boyacá, piede- monte del valle del Magdalena medio, Colombia. Biomedica 26 (Suppl.1): 82-94.

Silveira FT, Ishikawa EA, de Souza AA, Lainson R 2002. An outbreak of cutaneous leishmaniasis among soldiers in Belém, Pará state, Brazil, caused by Leishmania (Viannia) lindenbergi $\mathrm{n}$. sp. A new leishmanial parasite of man in the Amazon Region. Parasite 9: 43-50.

SIVIGILA - Sistema de Vigilancia en Salud Publica 2012. Estadísticas de vigilancia rutinaria. Available from: ins.gov.co/lineasde-accion/Subdireccion-Vigilancia/sivigila/Paginas/vigilanciarutinaria.aspx.

Souza NA, Andrade-Coelho CA, Vilela ML, Peixoto AA, Rangel EF 2002. Seasonality of Lutzomyia intermedia and Lutzomyia whitmani (Diptera: Psychodidae: Phlebotominae), occurring sympatrically in area of cutaneous leishmaniasis in the state of Rio de Janeiro, Brazil. Mem Inst Oswaldo Cruz 97: 759-765.

Travi BL, Adler GH, Lozano M, Cadena H, Montoya-Lerma J 2002. Impact of habitat degradation on Phlebotominae (Diptera: Psychodidae) of tropical dry forests in northern Colombia. $J$ Med Entomol 39: 451-456.

Travi BL, Montoya J, Solarte Y, Lozano L, Jaramillo C 1988. Leishmaniasis in Colombia. I. studies on Phlebotomine fauna associated with endemic foci in the Pacific Coast region. Am J Trop Med Hyg 39: 261-266.

Vásquez-Trujillo A 2006. Registro de leishmaniasis cutánea en caninos presentes en zonas peri-urbana de Villavicencio, Meta, y su importancia en la salud pública. Orinoquia 10: 79-86.

Vásquez-Trujillo A, Santamaría-Herreño E, González-Reina AE, Buitrago-Alvarez LS, Góngora-Orjuela A, Cabrera-Quintero OL 2008. Lutzomyia antunesi as suspected vector of cutaneous leishmaniasis in the Orinoquian region of Colombia. Rev Salud Publica 10: 625-632.

Velez ID, Hendrickx E, Robledo S, Agudelo S 2001. Leishmaniosis cutánea en Colombia y género. Cad Saude Publica 17: 171-180.

Young DG, Duncan MA 1994. Guide to the identification and geographic distribution of Lutzomyia sand flies in Mexico, the West Indies, Central and South America (Diptera: Psychodidae). Mem Am Entomol Inst 54: 1-881.

Young DG, Lawyer PG 1987. New world vectors of leishmaniasis. In KF Harris (ed.), Current tropics in vector research, Vol. 4, Springer-Verlag, New York, p. 29-71. 